University of Nebraska - Lincoln

DigitalCommons@University of Nebraska - Lincoln

Faculty Publications from the Harold W. Manter Laboratory of Parasitology

$8-2000$

\title{
Emergence of Third-Stage Larvae of Umingmakstrongylus pallikuukensis from Three Gastropod Intermediate Host Species
}

\author{
Susan K. Kutz \\ Western College of Veterinary Medicine \\ Eric P. Hoberg \\ United States Department of Agriculture, Agricultural Research Service, geocolonizer@gmail.com \\ Lydden Polley \\ Western College of Veterinary Medicine, lydden.polley@usask.ca
}

Follow this and additional works at: https://digitalcommons.unl.edu/parasitologyfacpubs

Part of the Parasitology Commons

\begin{abstract}
Kutz, Susan K.; Hoberg, Eric P.; and Polley, Lydden, "Emergence of Third-Stage Larvae of Umingmakstrongylus pallikuukensis from Three Gastropod Intermediate Host Species" (2000). Faculty Publications from the Harold W. Manter Laboratory of Parasitology. 334.

https://digitalcommons.unl.edu/parasitologyfacpubs/334
\end{abstract}

This Article is brought to you for free and open access by the Parasitology, Harold W. Manter Laboratory of at DigitalCommons@University of Nebraska - Lincoln. It has been accepted for inclusion in Faculty Publications from the Harold W. Manter Laboratory of Parasitology by an authorized administrator of DigitalCommons@University of Nebraska - Lincoln. 


\title{
EMERGENCE OF THIRD-STAGE LARVAE OF UMINGMAKSTRONGYLUS PALLIKUUKENSIS FROM THREE GASTROPOD INTERMEDIATE HOST SPECIES
}

\author{
S. J. Kutz, E. P. Hoberg ${ }^{\star}$, and L. Polley \\ Department of Veterinary Microbiology, Western College of Veterinary Medicine, 52 Campus Drive, University of Saskatchewan, Saskatoon, \\ Saskatchewan, Canada S7N 5B4
}

\begin{abstract}
We investigated the emergence of third-stage larvae (L3) of Umingmakstrongylus pallikuukensis from the slugs Deroceras laeve, Deroceras reticulatum, and the snail Catinella sp. in the laboratory and from D. laeve on the tundra. Thirdstage larvae emerged from 8 of $8 \mathrm{D}$. laeve and 8 of $8 \mathrm{D}$. reticulatum housed at $20 \mathrm{C}$ in darkness and from 9 of $10 \mathrm{D}$. laeve and 5 of 5 Catinella sp. housed at $21 \mathrm{C}$ with $10-12 \mathrm{hr}$ of light/day. Larvae emerged from D. laeve and D. reticulatum over a wide range of infection intensities (2-179 and 20-65, respectively), and the patterns of emergence were independent of intensity. The majority of the L3 emerged from most of the Deroceras spp. by 58 or 60 days postinfection (PI). Lower rates of emergence were observed from Catinella sp. Larvae emerged from $D$. laeve on the tundra by $10 \mathrm{wk}$ PI and were recovered from the vegetation in some experimental enclosures the following year. Third-stage larvae survived in tap and distilled water at $0-4 \mathrm{C}$ for 13 mo. Emergence of L3 of $U$. pallikuukensis from the intermediate host may increase the temporal and spatial availability of L3 and enhance their survival and transmission.
\end{abstract}

Umingmakstrongylus pallikuukensis, a protostrongylid lungworm known only in muskoxen (Hoberg et al., 1995) is present at a high prevalence and intensity in the host population west of Kugluktuk, Nunavut, Canada (Gunn and Wobeser, 1993). Similar to other protostrongylids, it requires a gastropod intermediate host $(\mathrm{IH})$ for development in the environment (Hoberg et al., 1995; Kutz et al., 1999).

Transmission of angiostrongylids and protostrongylids typically occurs when the definitive host (DH) ingests gastropods containing infective third-stage larvae (L3) (Anderson, 1992). For some species within the Angiostrongylidae and the related Protostrongylidae, however, L3 emerge from the live IH and transmission may occur when these emerged L3 are ingested by the DH (Heyneman and Lim, 1967; Boev, 1975). Notably, among the Angiostrongylidae, the L3 of Angiostrongylus cantonensis and Angiostrongylus costaricensis are known to emerge from their IH (Heyneman and Lim, 1967; Ubelaker et al., 1980), a phenomenon considered important for transmission.

An extensive European and Russian literature on the protostrongylids, summarized by Boev (1975), includes the majority of the reports on L3 emergence. Among the Muelleriinae and Protostrongylinae, emergence of L3 from living gastropods has been reported for Muellerius capillaris, Cystocaulus ocreatus, Protostrongylus rufescens, Protostrongylus davtyani, Protostrongylus tauricus, and Protostrongylus pulmonalis and/or Protostrongylus kamenskyi (see Boev, 1975), Protostrongylus stilesi (see Monson and Post, 1972), and Protostrongylus boughtoni (see Kralka and Samuel, 1984). There have been no reports of L3 emergence among the Elaphostrongylinae (Kontrimavichus et al., 1976; Anderson, 1992), but emergence of L3 of Parelaphostrongylus sp. (originating from Dall's sheep [Ovis dalli]) from the slug Deroceras laeve has been observed in the laboratory (S. J. Kutz, unpubl. obs.).

Experimentally, emerged L3 of $P$. boughtoni and A. cantonensis produce patent infections in their respective DH (Hey-

Received 3 August 1999; revised 6 December 1999; accepted 6 December 1999.

* United States Department of Agriculture, Agricultural Research Service, Biosystematics and National Parasite Collection Unit, BARC East No. 1180, 10300 Baltimore Avenue, Beltsville, Maryland 20705. neman and Lim, 1967; Richards and Merritt, 1967; Kralka and Samuel, 1984), and emerged L3 of $U$. pallikuukensis can develop to adults in muskoxen (Kutz et al., 1999). Larval emergence is considered important in the epidemiology of $M$. capillaris, C. ocreatus, and A. cantonensis (Heyneman and Lim, 1967; Boev, 1975). Other authors, however, question the significance of larval emergence and believe the main route of infection for the DH is by ingestion of infected gastropods (Kralka and Samuel, 1984; Anderson, 1992). Patterns of emergence for larval protostrongylids from IH, factors affecting emergence, and its epidemiological significance have not been investigated in detail.

The objectives of the present study were: (1) to investigate in the laboratory the patterns of L3 emergence of $U$. pallikuukensis from 2 potential natural and 1 laboratory $\mathrm{IH}$; and (2) to determine whether L3 emerge from $D$. laeve under natural conditions in the Arctic. We propose that emergence of L3 of $U$. pallikuukensis is a natural phenomenon that occurs consistently from different IH species, that it is not a function of infection intensity, and that it may be epidemiologically important in the maintenance of this parasite in muskox populations.

\section{MATERIALS AND METHODS}

\section{Laboratory experiments}

Infection of gastropods: First-stage larvae (L1) were obtained from the feces of an experimentally infected muskox (Kutz et al., 1999). Deroceras laeve and Catinella sp., both potential natural IH, were collected near the Coppermine and Rae rivers near Kugluktuk $\left(67^{\circ} 49^{\prime} \mathrm{N}\right.$, $115^{\circ} 08^{\prime} \mathrm{W}$ ), Nunavut, Canada and Deroceras reticulatum, a laboratory IH, were obtained from a laboratory colony (Kutz et al., 1999). For $D$. laeve and $D$. reticulatum, only adult specimens were used $(\geq 15 \mathrm{mg}$ and $400 \mathrm{mg}$, respectively), but because few Catinella sp. were available, specimens with both 2 and 3 whorls were used. Prior to experimental infection with $U$. pallikuukensis, the feet of all wild-caught gastropods were examined for lesions indicative of existing protostrongylid infections (S. J. Kutz, unpubl. obs.). No such lesions were seen on any of the specimens examined.

Gastropods were exposed in groups to L1 on filter paper in plastic petri dishes over a single 3-hr period (Hoberg et al., 1995; Kutz et al., 1999). Additional gastropods, not exposed to L1, were used as controls in the experiments with $D$. laeve and Catinella sp.. Four experiments were established at 2 different levels of L1 exposure: in experiments 1 (D. laeve) and 2 (D. reticulatum) slugs were each exposed to 1,000 L1/ slug; in experiments 3 (D. laeve) and 4 (Catinella sp.) gastropods were each exposed to $500 \mathrm{~L} 1 /$ gastropod (Table I). 
TABLE I. Emergence of L3 of Umingmakstrongylus pallikuukensis from 3 species of gastropods under laboratory conditions.

\begin{tabular}{|c|c|c|c|c|c|c|c|}
\hline $\begin{array}{l}\text { Experi- } \\
\text { ment }\end{array}$ & $\begin{array}{l}\text { Gastropod } \\
\text { species }\end{array}$ & $\begin{array}{c}\text { Number of } \\
\text { gastropods } \\
\text { infected/control }\end{array}$ & L1/gastropod* & $\begin{array}{c}\text { Temperature } \\
\left({ }^{\circ} \mathrm{C}\right)\end{array}$ & $\begin{array}{c}\text { Days of } \\
\text { experiment }(\mathrm{PI})\end{array}$ & $\begin{array}{l}\text { Days between } \\
\text { examination }\end{array}$ & $\begin{array}{c}\text { Range of } \\
\text { L3/gastropod }\end{array}$ \\
\hline $2 \dagger$ & Deroceras reticulatum & $8 / 0$ & 1,000 & $20 \pm 0.5$ & $14-58$ & $2-5$ & $20-65$ \\
\hline $3 末$ & Deroceras laeve & $10 / 10$ & 500 & $21 \pm 1.0$ & $20-60$ & $2-4$ & $1-19$ \\
\hline $4 \$$ & Catinella & $5 / 6$ & 500 & $21 \pm 1.0$ & $24-60$ & $2-8$ & $2-12$ \\
\hline
\end{tabular}

* Number of L1 to which each gastropod was exposed.

$\dagger$ In total darkness in temperature-controlled incubator.

† In 12-14 hr light/day at room temperature.

Gastropod maintenance and examination: Gastropods were housed initially in Rubbermaid ${ }^{\circledR}$ containers (Kutz et al., 1999). At 12-24 days postinfection (PI) (see Table I), they were placed individually in moistened glass petri dishes (50 mm inside diameter) containing lettuce, carrots, and chalk. Dishes and gastropods were examined for L3 frequently (see Table I). Foot lesions and emerging L3 were detected by examining the foot surface using a dissecting microscope with overhead lighting. Gastropods were then transferred to new sterilized petri dishes with fresh food. The uneaten food was removed from the old dishes, water was added to the lids and bases of the dishes, and these were examined with a dissecting microscope. The food removed was placed in individual $100-\mathrm{ml}$ glass containers with approximately $80 \mathrm{ml}$ of tap water. The water in the containers was agitated vigorously in order to dislodge larvae from the food. After $16-24 \mathrm{hr}$ in the light, at $21 \pm 1 \mathrm{C}$, the sediment was examined for larvae. At the end of each experiment, gastropods were killed, digested (Hoberg et al., 1995), and the remaining larvae counted and classified to stage of development.

Analysis: It was assumed that all L3 produced in each gastropod were recovered by examination of the dishes and vegetation and by digestion. The total number of L3 for each gastropod was determined by adding the number of L3 that emerged during the experiment to the number recovered by digestion at the end of the experiment. The cumulative proportion of L3 that had emerged from an individual gastropod by a given sampling day was the sum of all the L3 that had emerged up to and including that day divided by the total L3 recovered from the gastropod. The mean cumulative proportion of emerged L3 in an experiment was calculated based only on gastropods from which at least $1 \mathrm{~L} 3 \mathrm{had}$ emerged during the experiment.

\section{Field experiments}

As part of an arctic field study of the development of U. pallikuukensis, we investigated L3 emergence under natural conditions. Wild- caught $D$. laeve were experimentally infected with $U$. pallikuukensis (225 L1/slug) (Kutz et al., 1999) and placed in enclosures (10 slugs/ enclosure) made from perforated plastic pails (150 mm high, $200 \mathrm{~mm}$ inside diameter) containing tundra and lined and covered with a fine netting. Enclosures were placed into the tundra so that the vegetation in the pails was at the same level as that outside. Experiments were established every $2 \mathrm{wk}$, from 19 June to 28 August 1997, in a mesic sedge meadow near Kugluktuk (Table II). Multiple control enclosures containing 10 uninfected slugs were established for each experiment.

Three enclosures were removed from each experiment every 2 wk and gastropods were recovered using a water bath technique (Kralka, $1986)$ and subsequently digested and examined for larvae. Some enclosures were left in the tundra over winter and were examined the following year. After the first mobile L3 was recovered by digestion from a slug in an experiment, the vegetation from some of the enclosures in that experiment was sampled at varying intervals for emerged L3 (Table II). To recover emerged L3, vegetation was clipped to the level of the soil and placed in a glass flask or jar. Initially (vegetation examined 28 August and 11 September 1997), approximately $250 \mathrm{ml}$ of tap water was added to each container that was then shaken vigorously. The sediment was examined for larvae after $24 \mathrm{hr}$. The vegetation from 11 September 1997 was re-examined on 12 September 1997 by adding 1 drop of Ivory ${ }^{\circledR}$ liquid dish detergent to $5 \mathrm{~L}$ of tap water and using 250 $\mathrm{ml}$ of this solution for the larval recovery. The sediment was examined after $24 \mathrm{hr}$. The detergent technique was used for all subsequent samples. After the vegetation was clipped, slugs were recovered from the remaining turf and examined for larvae by digestion.

\section{Survival of L3}

Live L3 that had emerged from $D$. reticulatum in a preliminary laboratory experiment were placed in $50 \mathrm{ml}$ of tap water $(80 \mathrm{L3})$ or distilled water (164 L3) in 125-ml Erlenmeyer flasks with a foam cork and

TABLE II. Emergence of L3 of U. pallikuukensis from D. laeve under field conditions.

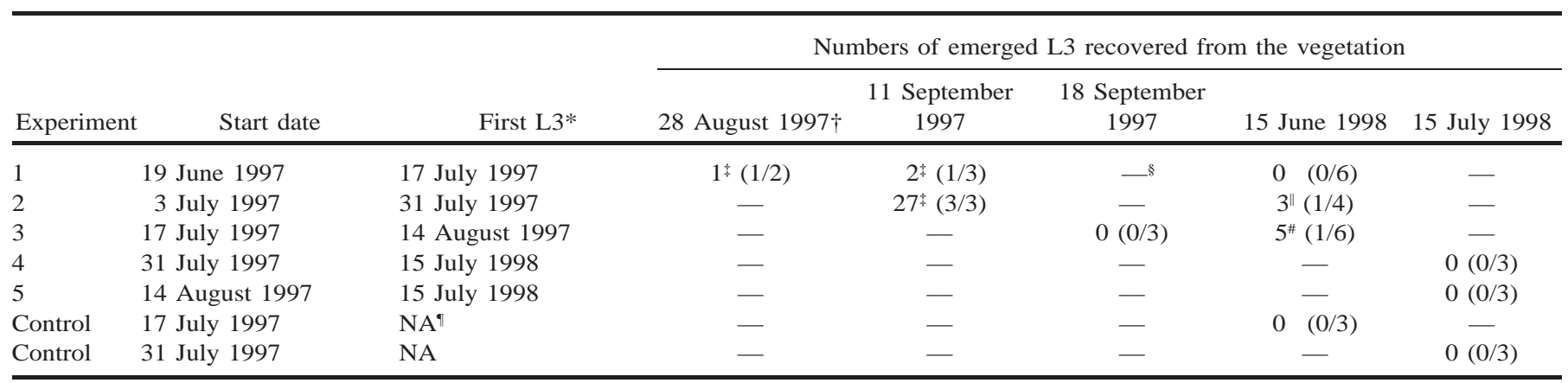

* Recovered by digestion of slugs.

$\dagger$ First value is the number of emerged L3 recovered; values in parentheses are numbers of enclosures with emerged L3/total enclosures examined.

$\ddagger$ All live L3.

$\S$ Not examined.

\| One live L3, 1 dead L3, 1 coiled L3.

\# Two live L3, 3 dead L3.

II No larvae recovered by digestion. 
placed at $0-4 \mathrm{C}$ (water froze at least once during this period). Water was added as needed to prevent dehydration. Larvae were examined at room temperature 13 mo later.

\section{RESULTS}

\section{Laboratory experiments}

Larval emergence: Third-stage larvae of $U$. pallikuukensis emerged from all the infected $D$. reticulatum and Catinella sp. and all but 1 infected $D$. laeve. Only L3 emerged and these were found on the sediment from the uneaten food and on the inside surfaces of the lids and bases of the petri dishes. Those found in water in the bases of the dishes or in the sediment from the food were usually motile, whereas those found in dry areas of the dishes were tightly coiled, coated with mucus, and adhered to the dish surface. When dislodged and placed in water, these larvae became motile. Early in the experiments, a few emerged L3 were still within the second-stage cuticular sheaths (CS2), but most sheaths were broken at the anterior end. CS2 were frequently observed free in the dishes. After day 30 PI, emerged L3 were usually free of the CS2. Larvae were not recovered from any control experiments with uninfected gastropods.

L3 were observed emerging during examination of the feet of live D. laeve. In experiment 3, on day $28 \mathrm{PI}$, a partially coiled L3 within the CS2 (broken at the anterior end) was expelled within a cloud of mucus from the foot of $1 \mathrm{D}$. laeve. This occurred from another $D$. laeve on day $40 \mathrm{PI}$ in experiment 1. Larvae were also observed actively emerging from slugs of this experiment on days 40 PI (2 L3 from 1 slug) and 46 PI (5 L3 from 1 slug). The cephalic extremities of the larvae were free from the foot of the slug and moving vigorously, whereas the posterior portions were still within the tissue. Dark pigment was visible in areas of the slug from which the larvae were emerging.

Emergence patterns: L3 emerged from D. laeve (experiments 1 and 3) were first observed on day 22 PI. Emerged L3 were first observed from $D$. reticulatum (experiment 2 ) on day 20 PI and from Catinella sp. (experiment 4) on day 38 PI. In experiments 3 and 4, however, examinations for L3 emergence were not started until days 20 and 26 PI, respectively, and L3 emerging earlier would not have been detected.

The pattern of emergence of $\mathrm{L} 3$ from $D$. laeve, D. reticulatum, and Catinella sp. differed among the experiments (Figs. 1-4). The total number of foot lesions observed in D. laeve in experiments 1 and 3 varied between days and individuals, but there was a trend for the lesion count to decrease as the proportion of emerged L3 increased (Fig. 1).

The total cumulative proportions of L3 that emerged from individual gastropods in each experiment relative to the intensities of infection are shown in Figures 5-8. There was 100\% L3 emergence from some $D$. laeve with both high (64 L3) and low (2 L3) intensities of infection (Figs. 5, 7). By the end of experiments with $D$. laeve and $D$. reticulatum the majority of the L3 had emerged from more than half of the slugs (Figs. 57). Levels of L3 emergence were lower in Catinella sp. with only 1 snail having lost more than half of its L3 by day 60 PI (Fig. 8). The patterns of L3 emergence from 6 individual $D$. laeve (from experiments 1 and 3) with similar cumulative proportions of emergence by the end of the experiments (approx- imately 0.6) were similar despite different intensities of infection (Fig. 9). Emergence at lower intensities of infection appears irregular because each L3 represents a higher proportion of the total than with higher intensities.

\section{Field experiments}

Varying numbers of slugs $(0-10)$ were recovered from the enclosures at each sampling period. All emerged L3 recovered from the vegetation in 1997 were alive, whereas some in 1998 were dead or coiled and nonmotile (Table II). More emerged L3 were recovered from the vegetation using the detergent technique after the water technique. In experiment 2, on 11 September 1997, 7, 1, and 1 live L3 were recovered from the vegetation of each of 3 enclosures examined using tap water. This vegetation was processed again using the detergent technique, and 3, 1, and 14 additional L3 were recovered from the 3 enclosures. In 1997, infected D. laeve were recovered from all enclosures with L3 on the vegetation, but in 1998 slugs were not recovered from the enclosures with L3 on the vegetation.

\section{Survival of L3}

Many of the emerged L3 held in water at 0-4 C for over 1 yr were still alive. From the tap water, 21 of the original $80 \mathrm{~L} 3$ were recovered, and of these, 1 was dead, 3 were active, and 17 were tightly coiled, the cuticle was intact, and there was no evidence of distortion or cellular deterioration. From the distilled water, 122 of the original 164 L3 were recovered, and of these, 7 were dead, 9 were active, and 106 were tightly coiled and appeared similar to the coiled L3 from tap water.

\section{DISCUSSION}

In the laboratory, L3 of $U$. pallikuukensis emerged from 3 species of gastropods, 2 of which occur in the Arctic where naturally infected muskoxen are found. The start of emergence did not coincide with initial appearance of L3 in the gastropods. At $20 \mathrm{C}, \mathrm{L} 1$ of $U$. pallikuukensis develop to motile L3 by days 12 and $15 \mathrm{PI}$ in $D$. laeve and $D$. reticulatum, respectively (S. J. Kutz, unpubl. obs.). In the present study, however, L3 did not emerge from these IH until days 20-22 (D. laeve) or 18-20 PI (D. reticulatum). This suggests that L3 need to reach a particular stage of development before emerging. Morphological and morphometric differences between the early motile L3 in $\mathrm{IH}$ and those recovered 3 wk later from the $\mathrm{IH}$ or those that had emerged (S. J. Kutz, unpubl. obs.) support this suggestion.

Differences in levels and patterns of emergence were observed among gastropod species. All the L3 had emerged from some D. laeve and Catinella sp. by day 60 PI, but no D. reticulatum had lost all their L3 by day 58 PI (Fig. 6). This difference may be related to the gastropod species. Deroceras reticulatum, unlike D. laeve and Catinella sp., does not occur in the Arctic, nor is it native to North America (Pilsbry, 1948). It is, therefore, an unlikely natural IH for $U$. pallikuukensis. Alternatively, the differences may be an artifact of the small number of gastropods in each experiment. The mean cumulative proportion of L3 emerging from Catinella sp. was considerably less than that from either of the slug species. Many of these snails underwent short periods of aestivation during the exper- 


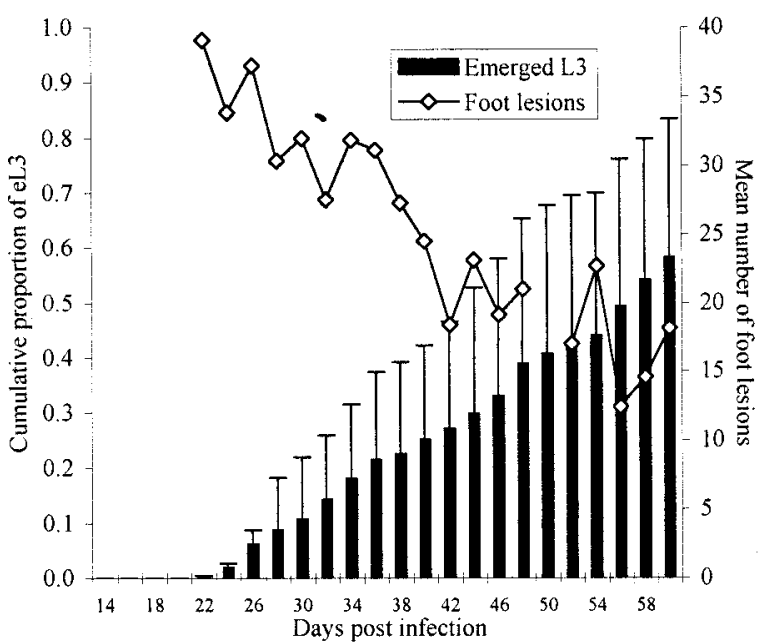

1

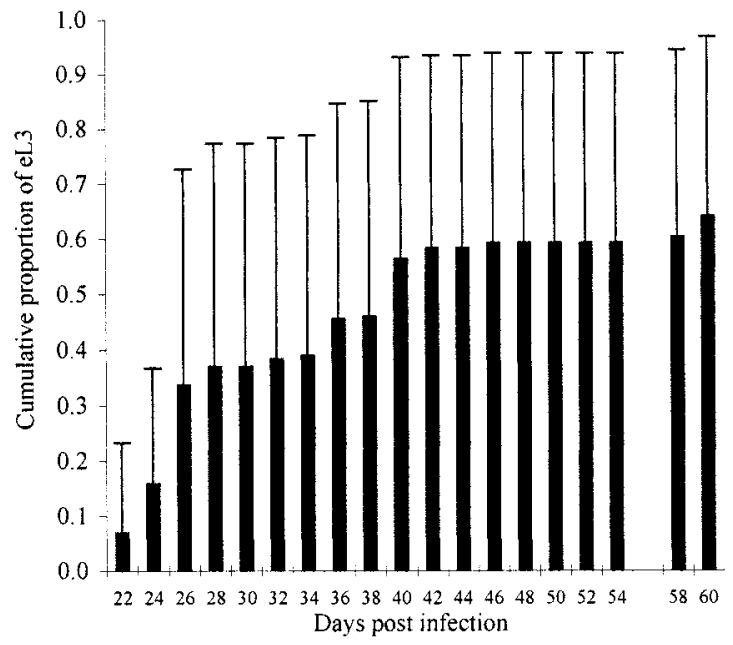

3

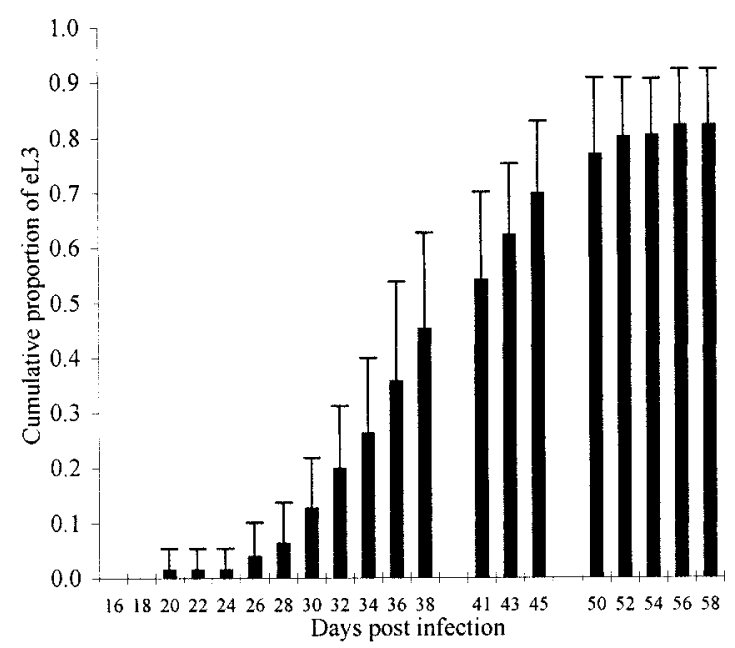

2

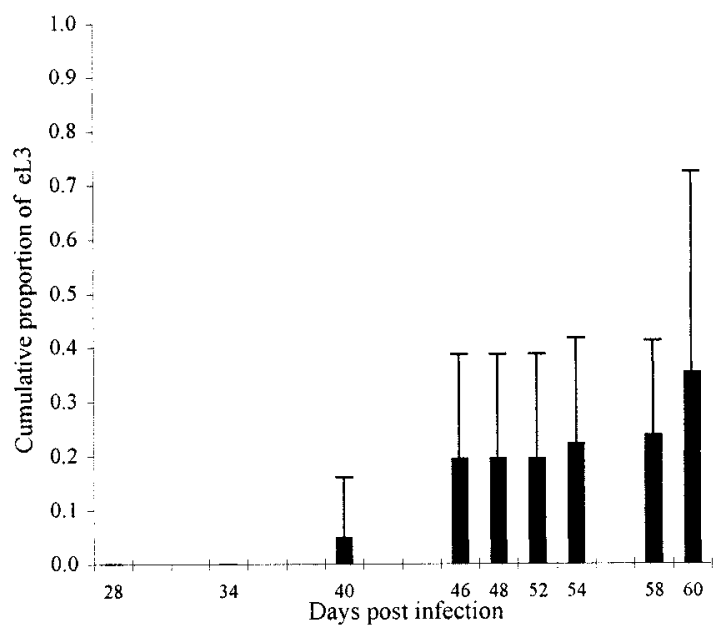

4

FIGURES 1-4. The mean cumulative proportions of third-stage larvae (eL3) that emerged from gastropods during each experiment. Each bar represents the mean cumulative proportion of L3 that had emerged up to that day relative to the total L3 (total L3 = L3 emerged by end of experiment + L3 recovered from the gastropod by digestion at the end of experiment). Error bars $=1 \mathrm{SD}$ of the mean of all gastropods (from which larvae emerged) within an experiment. 1. Experiment 1 with Deroceras laeve. Slugs were examined every second day. Also shown are the mean number of lesions in the feet of 8 slugs (not examined on day $50 \mathrm{PI}$ ). 2-4. Gastropods were examined only on the days indicated by numbers. 2. Experiment 2 with Deroceras reticulatum. 3. Experiment 3 with D. laeve. 4. Experiment 4 with Catinella sp.

iment, and because IH activity may be necessary for L3 emergence (Boev, 1975), this aestivation may have inhibited emergence. In addition, aestivation can delay development of Muellerius cf. capillaris (Solomon et al., 1996) and may have been responsible for the asynchronous development of $U$. pallikuukensis in Catinella sp. (at day 60 PI second-stage larvae [L2] as well as L3 were recovered). Fewer larvae at the L3 stage in the snails, compared to $D$. laeve, could result in a lower level of emergence.

Some authors suggest that L3 emergence may be a result of unnaturally high intensities in laboratory infections (Kralka and Samuel, 1984). Gastropods naturally infected with protostrongylids typically have low intensities of infection, but occasionally higher intensities do occur (for example, 75 and 97 larvae of $P$. tenuis in individual $D$. laeve; Lankester and Anderson,
1968; Maze and Johnstone, 1986). Data are not available for the intensity of natural infections of IH with $U$. pallikuukensis; however, in the present study, L3 emerged over a wide range of intensities of infection and there was no evidence that the different intensities affected the cumulative proportion or rate of emergence (Figs. 5-7, 9).

The L3 found on the vegetation in the enclosures of the field experiments may have emerged from live or dead slugs; fewer than the original 10 slugs were recovered from the enclosures, suggesting some mortality. Based on the high proportion of L3 that emerged from live IH in the laboratory, it is likely that at least some of the L3 emerged from live slugs in the field. Whether L3 on the vegetation in the spring of 1998 emerged the previous fall or that spring could not be determined. The apparent absence of L3 emergence in field experiments 4 and 


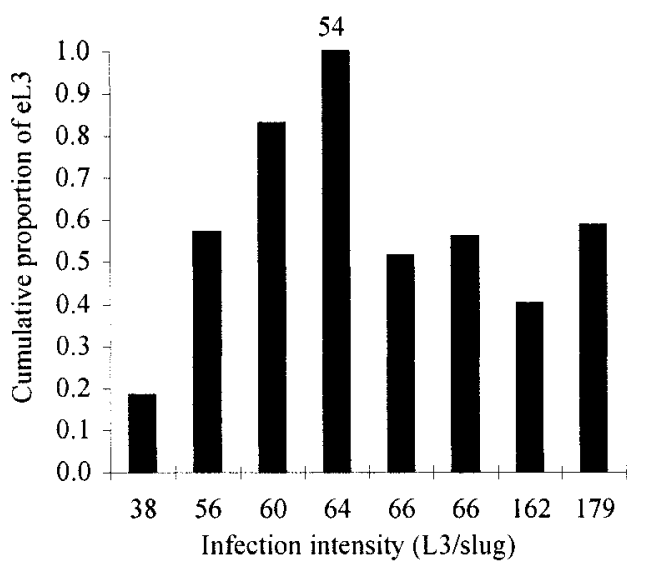

5

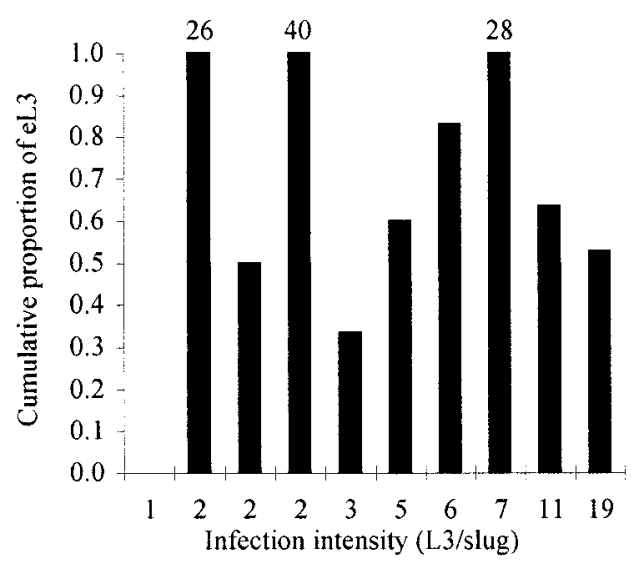

7

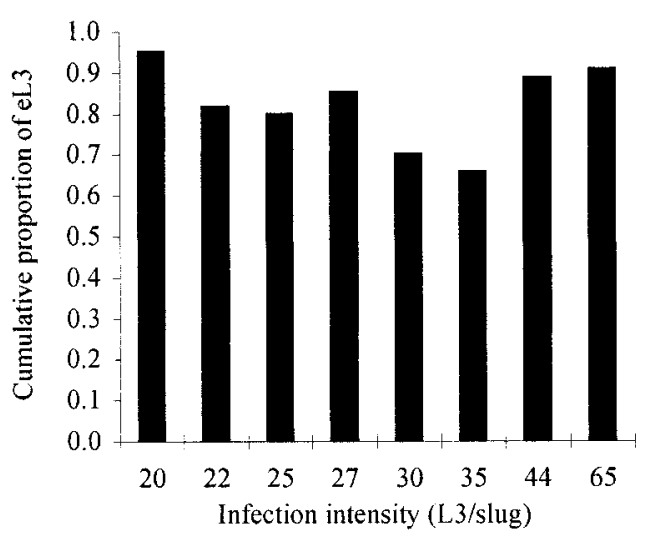

6

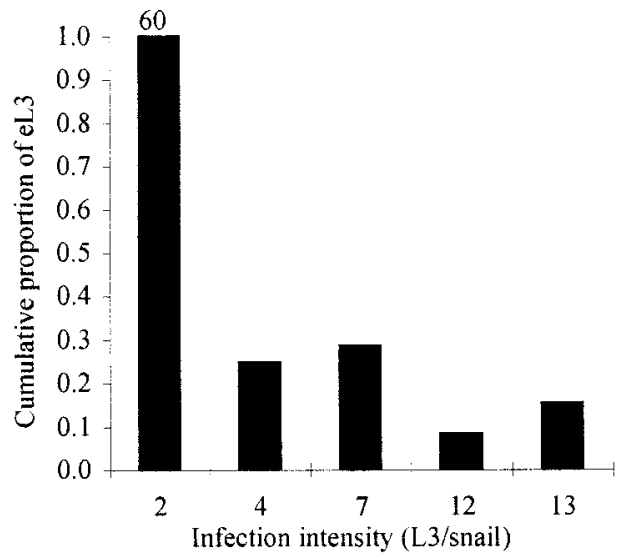

8

FIGURES 5-8. Proportion of third-stage larvae (eL3) that emerged relative to intensity of infection. Each bar represents the proportion of the total L3 within an individual gastropod that emerged during the experiment. The total number of L3 (defined in Figs. 1-4) recovered from each individual gastropod is shown on the x-axis. Where numbers are present above the bars they indicate the number of days PI by which $100 \%$ of the L3 had emerged from that gastropod. Experiments 1, 3, and 4 ended on day 60 PI; experiment 2 on day 58 PI. 5. Experiment 1 with $D$. laeve. 6. Experiment 2 with D. reticulatum. 7. Experiment 3 with D. laeve. 8. Experiment 4 with Catinella sp.

5 may have been because these larvae had recently developed to L3 (L2 were found in some digested slugs) and were not sufficiently developed to emerge.

The number of L3 that emerged from the gastropods in the field may have been underestimated by our sampling techniques. First, only the vegetation was examined, not the sides of the enclosures or the soil within the enclosures where slugs were frequently observed. Second, the detergent technique seemed to improve larval recovery. It is likely, therefore, that not all L3 were recovered from the vegetation on 28 August 1997, when plain water was used.

Two different mechanisms for emergence of U. pallikuukensis from $D$. laeve were observed in the present study, i.e., expulsion of L3 with mucus of the slug and vigorous movements of the L3. These 2 mechanisms may be associated with the presence or absence of the CS2. Expulsion of L3 of $P$. boughtoni contained within the CS2 may be associated with contractions of the gastropod's foot muscle or an active immune response by the IH (Kralka and Samuel, 1984). In contrast, protostrongylid L3 released from CS2 may have increased motility (Gerichter, 1948; Rose, 1957; Beresford-Jones, 1966) that may facilitate active larval emergence. There appear to be differences among the Protostrongylidae in whether they emerge with or without the CS2 (Monson and Post, 1972; Boev, 1975; Kralka and Samuel, 1984). This and other aspects of L3 emergence may be phylogenetically linked traits that should be investigated within the context of recent phylogenetic studies for the Protostrongylidae (Carreno and Hoberg, 1999).

L3 examined after $13 \mathrm{mo}$ in water at 0-4 C were coiled, showed no signs of degeneration, and were thought to be alive; however, the infectivity was not determined. Survival of L3 in cold water and subsequent infectivity is of significance because the potential terrestrial IH in the Arctic (D. laeve and Catinella sp.) live in moist habitats, often in mesic or wet sedge meadows, lake shores, or riverbanks (S. J. Kutz, unpubl. obs.). Deroceras laeve in particular is well adapted to wet habitats, hatching and remaining mobile when submerged in water (Rollo and Shibata, 1991). In addition, U. pallikuukensis can develop in at 


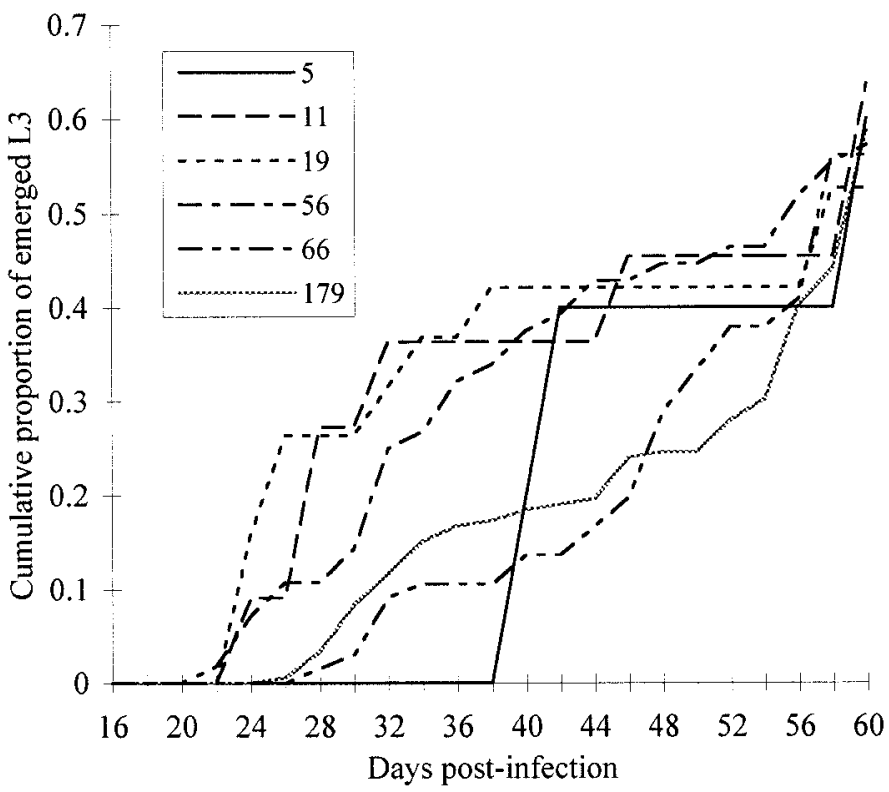

FIGURE 9. Patterns of emergence of L3 from individual D. laeve with different intensities of infection (5-179 L3) (slugs from experiments 1 and 3) but similar proportions of emerged L3 by day 60 PI.

least 1 freshwater arctic species, the snail Aplexa hypnorum (S. J. Kutz, unpubl. obs.). Larval emergence with subsequent survival in water, perhaps facilitated by the ability to feed when the CS2 is absent, suggest that L3 free in the environment may be a source of infection for muskoxen. Larvae emerging on to dry surfaces may use a different strategy for survival. The thick coating observed on these L3, possibly mucus produced by the gastropods, may be instrumental in protecting the L3 from desiccation and extending its survival in the environment.

Survival and mobility of free-living L3 of other species of protostrongylids have been only superficially investigated. Varying degrees of resistance to desiccation but not to sunlight ( $M$. capillaris and $C$. ocreatus), survival after repeated cycles of freezing and thawing associated with overwintering $(C$. ocreatus) (see Boev, 1975), survival in water, and after the death of the IH (Elaphostrongylus rangiferi) (see Kontrimavichus et al., 1976) have been reported. In addition, horizontal, but no vertical, mobility of emerged L3 has been reported for E. rangiferi (see Kontrimavichus et al., 1976). Understanding the survival, mobility, and subsequent infectivity of emerged $U$. pallikuukensis L3 is important to better assess the significance of larval emergence.

Transmission of $U$. pallikuukensis requires temporal and spatial overlap of L1 with gastropods and, according to the current understanding of protostrongylid life cycles, of gastropods containing infective L3 with the DH (Anderson, 1992). In the Arctic, such transmission of $U$. pallikuukensis and other nematodes to the DH may be limited to seasonally defined periods (Hoberg et al., 1999). The short arctic summers may limit when gastropods are active. Emerged L3 that survive ambient conditions on the vegetation may be available when the gastropods are not and may be more widely distributed in the environment than the gastropods. This enhanced life span and dispersal of emerged L3 would increase their availability on temporal and spatial scales and may eliminate the necessity for direct gastropod-muskox contact.

Spatial and temporal overlap of muskoxen with gastropods at high densities may be limited by seasonal migrations (Gunn and Fournier, 2000) or seasonal dietary shifts (thus changes in habitat use) by muskoxen (Robus, 1981; O'Brian, 1988; Gunn and Sutherland, 1997). For example, gastropod densities may be greatest in muskox wintering areas and yet their availability to muskoxen would be restricted in the winter. If, however, L3 emerge and survive ambient conditions on the vegetation, they may be available during the winter when gastropods are hibernating but muskoxen are present.

In the present study L3 emerged over an extended time period. A similar pattern in nature could result in L3 emerging on to many different areas of the vegetation during normal summer gastropod activity. If arctic gastropods exhibit similar circadian activity patterns, influenced by temperature, humidity, and wind, as has been reported for temperate species (Dainton, 1989; Kaufmann, 1990; Rollo and Shibata, 1991), they are probably not available to the muskoxen at all times of the day. Larval emergence, however, would provide multiple foci of infection from a single gastropod, on vegetation or in the water, available $24 \mathrm{hr}$ a day, increasing the probability for transmission compared to that dependent on ingestion of the gastropod. This strategy may be particularly important in parasite transmission from heavily infected gastropods.

Larval emergence may be linked to the life history of the gastropods and may increase L3 availability after death of the IH. For example, if in some years, as has been proposed for $E$. rangiferi in Norway (Halvorsen and Skorping, 1982), larvae of $U$. pallikuukensis require 2 summer seasons to develop to L3, it would be the large slugs, infected the previous year, that would contain L3 by the following midsummer. In southern Ontario, Canada, large D. laeve (those that have overwintered) disappear from the population in August and September (Lankester and Anderson, 1968). If a similar life cycle occurs in the Arctic, without emergence, all L3 in these large slugs would be lost in the second summer when the slugs died. Alternatively, L3 emerging on to vegetation or into the water before the IH dies may remain available for transmission. Observations in the present study and by other authors (Rose, 1957; Cheng and Alicata, 1964) suggest that L3 emergence may increase in unhealthy gastropods.

In conclusion, based on laboratory and field data, emergence of L3 from the IH appears to be an inherent trait of $U$. pallikuukensis. This alternate pathway for transmission may be of importance in the natural host-parasite system by increasing larval availability spatially and temporally, perhaps extending or eliminating the narrow and seasonally defined windows of transmission. Recognition that emergence of L3 of U. pallikuukensis, and perhaps other protostrongylids, may be a natural and epidemiologically significant phenomenon broadens our current understanding of transmission dynamics and life history patterns for lungworms (e.g., Anderson, 1992). To understand this phenomenon further, and to test the hypotheses outlined in this paper, it is important to determine the extent of L3 emergence in the field, the survival and subsequent infectivity of emerged larvae under natural conditions, the factors affecting emergence, and how the life history and behavioral patterns of 
the gastropod intermediate hosts relate to the life history strategies of muskoxen definitive hosts.

\section{ACKNOWLEDGMENTS}

We thank Christabelle Westwood, Monica Kapakatoak, Shannon Ekhiohina, Damian Panayi, Theresa Westwood, Rita Kutz, Mindy Willet, Lois Wooding, Dave and Mary Elder, and Harold Mulder for assistance with the field studies and the Kugluktuk Hunters' and Trappers' Organization and the Department of Resources, Wildlife and Economic Development (DRWED), Kitikmeot Region, Nunavut for logistical support. Brent Wagner, Angela Schneider, Rick Espie, and Nicole Paquette assisted with maintenance of gastropods. Jim Van Es kindly identified gastropods, John Nishi provided logistical support and critical comments on experimental design, and Anne Gunn and 2 anonymous reviewers commented on an earlier version of this manuscript. This work has been supported by DRWED, Merial Canada Inc., a Western College of Veterinary Medicine Interprovincial Graduate Scholarship, a Wildlife Disease Association Graduate Student Scholarship, the Western College of Veterinary Medicine Wildlife Health Fund, and the Northern Scientific Training Program DIAND, Government of Canada.

\section{LITERATURE CITED}

Anderson, R. C. 1992. Nematode parasites of vertebrates: Their development and transmission. CAB International, Wallingford, U.K., $578 \mathrm{p}$.

BERESFORD-Jones, W. P. 1966. Observations on Muellerius capillaris (Muller, 1889), Cameron, 1927 I.-The bionomics and development in Trichia hispida (Linnaeus) of larvae obtained from sheep grazed on permanent pasture. Research in Veterinary Science 7: 61-66.

Boev, S. N. 1975. Protostrongylids. Fundamentals of nematology, Vol. 25. Helminthological Laboratory, Academy of Sciences of the USSR, Moscow. [English Translation, 1984, U.S. Department of Agriculture, Washington, D.C., and Amerind Publishing Co., New Delhi, India, 337 p.]

Carreno, R. A., AND E. P. Hoberg. 1999. Evolutionary relationships among the Protostrongylidae Leiper, 1926 (Nematoda: Metastrongyloidea) as inferred from morphological characters. Journal of Parasitology 85: 638-648.

Cheng, T. C., And J. E. Alicata. 1964. Possible role of water in the transmission of Angiostrongylus cantonensis (Nematoda: Metastrongylidae). Journal of Parasitology 50: 39-40.

DAINTON, B. 1989. Field and laboratory observations on slug and snail behavior. In Slugs and snails in world agriculture: Proceedings of a symposium organized by the British Crop Protection Council in Association with the Malacological Society of London, No. 41, I. Henderson (ed.). British Crop Protection Council, Guildford, U.K., p. 201-207.

Gerichter, C. B. 1948. Observations on the life history of lung nematodes using snails as intermediate hosts. American Journal of Veterinary Research 9: 109-112.

GunN, A., AND B. FourniER. 2000. Calf survival and seasonal migrations of a mainland muskox population. Northwest Territories Department of Resources, Wildlife and Economic Development. File Rep. No. 123, 113 p.

, AND M. SuTHERLAND. 1997. Muskox diet and sex-age composition in the Central Arctic Coastal Mainland (Queen Maud Gulf Area) 1988-1991. Northwest Territories Department of Resources, Wildlife and Economic Development. Manuscript Rep. No. 95, 67 p.

- AND G. WoBESER. 1993. Protostrongylid lungworm infection in muskoxen, Coppermine, N.W.T., Canada. Rangifer 13: 45-47.

Halvorsen, O., AND A. Skorping. 1982. The influence of temperature on growth and development of the nematode Elaphostrongylus ran- giferi in the gastropods Arianta arbustorum and Euconulus fulvus. Oikos 38: 285-290.

Heyneman, D., AND B.-L. LiM. 1967. Angiostrongylus cantonensis: Proof of direct transmission with its epidemiological implications. Science 158: 1057-1058.

Hoberg, E. P., K. J. Monsen, S. Kutz, and M. S. Blouin. 1999. Structure, biodiversity and historical biogeography of nematode faunas in holarctic ruminants: Morphological and molecular diagnoses for Teladorsagia boreoarcticus sp. n. (Nematoda: Ostertagiinae), a dimorphic cryptic species in muskoxen (Ovibos moschatus). Journal of Parasitology 85: 910-934.

-, L. Polley, A. GunN, AND J. S. Nishi. 1995. Umingmakstrongylus pallikuukensis gen. nov. et sp. nov. (Nematoda: Protostrongylidae) from muskoxen, Ovibos moschatus, in the central Canadian Arctic, with comments on biology and biogeography. Canadian Journal of Zoology 73: 2266-2282.

Kaufman, B. Z. 1990. Some features of the preferential behavior of the terrestrial slug, Deroceras reticulatum. Zoologicheskiy Zhurnal 69: $145-147$.

Kontrimavichus, V. L., S. L. Delyamure, and S. N. Boev. 1976. Metastrongyloids of domestic and wild animals. Nauka Publishers, Moscow. [English translation, 1985, Amerind Publishing Co. Pvt. Ltd., New Delhi, India, 298 p.].

KRALKA, R. A. 1986. Population characteristics of terrestrial gastropods in boreal forest habitats. American Midland Naturalist 115: 156164.

, AND W. M. SAMUEL. 1984. Emergence of larval Protostrongylus boughtoni (Nematoda: Metastrongyloidea) from a snail intermediate host and subsequent infection in the domestic rabbit (Oryctolagus cuniculus). Journal of Parasitology 70: 457-458.

Kutz, S. J., E. P. Hoberg, And L. Polley. 1999. Experimental infections of muskoxen (Ovibos moschatus) and domestic sheep with Umingmakstrongylus pallikuukensis (Nematoda: Protostrongylidae): Parasite development, population structure and pathology. Canadian Journal of Zoology 77: 1562-1572.

LANKester, M. W., AND R. C. Anderson. 1968. Gastropods as intermediate hosts of Pneumonstrongylus tenuis Dougherty of whitetailed deer. Canadian Journal of Zoology 46: 373-383.

Maze, R. J., And C. Johnstone. 1986. Gastropod intermediate hosts of the meningeal worm Parelaphostrongylus tenuis in Pennsylvania: Observations on their ecology. Canadian Journal of Zoology 64: 185-188.

Monson, R. A., AND G. Post. 1972. Experimental transmission of Protostrongylus stilesi to bighorn-mouflon sheep hybrids. Journal of Parasitology 58: 29-33.

O'BriAn, C. M. 1988. Characterization of muskox habitat in northeastern Alaska. M.S. Thesis. University of Alaska, Fairbanks, Alaska, $114 \mathrm{p}$.

Pilsbry, H. A. 1948. Land Mollusca of North America (north of Mexico). Monograph No. 3, Vol. II, Part 2. George W. Carpenter Fund for the Encouragement of Original Scientific Research, Philadelphia, $1113 \mathrm{p}$.

Richards, C. S., AND J. W. MerritT. 1967. Studies on Angiostrongylus cantonensis in molluscan intermediate hosts. Journal of Parasitology 53: 382-388.

Robus, M. A. 1981. Muskox habitat and use patterns in northeastern Alaska. M.S. Thesis. University of Alaska, Fairbanks, Alaska, 116 p.

Rollo, C. D., AND D. M. ShiBATA. 1991. Resilience, robustness, and plasticity in a terrestrial slug, with particular reference to food quality. Canadian Journal of Zoology 69: 978-987.

Rose, J. H. 1957. Observations on the larval stages of Muellerius capillaris within the intermediate hosts Agriolimax agrestis and A. reticulatus. Journal of Helminthology 31: 1-16.

Solomon, A., I. PAPERnA, AND A. MARKovics. 1996. The influence of aestivation in land snails on the larval development of Muellerius cf. capillaris (Metastrongyloidea: Protostrongylidae). International Journal for Parasitology 26: 363-367.

Ubelaker, J. E., G. R. Bullick, AND J. CARuso. 1980. Emergence of third-stage larvae of Angiostrongylus costaricensis Morera and Cespedes 1971 from Biomphalaria glabrata (Say). Journal of Parasitology 66: 856-857. 